\title{
Robert Walser: El más solitario de los escritores. La influencia de su enfermedad en su creación literaria
}

\section{Robert Walser: the loneliest writer. The influence of his disease on his literary work}

Robert Walser (1878-1956) is an important but unknown European writer of the twentieth century. He was also a mysterious and solitary man who lived at the margins of society. After the questionable diagnosis of schizophrenia, he nearly stopped writing and spent almost three decades in two Swiss psychiatric hospitals. The originality of his work, undoubtedly conditioned by his mental disorder, renders interesting a review of his life and a discussion of the possible differential diagnosis of his disease.

(Rev Med Chile 2010; 138: 373-378).

Key words: Diagnosis, differential; Literature, modern; Schizophrenia.

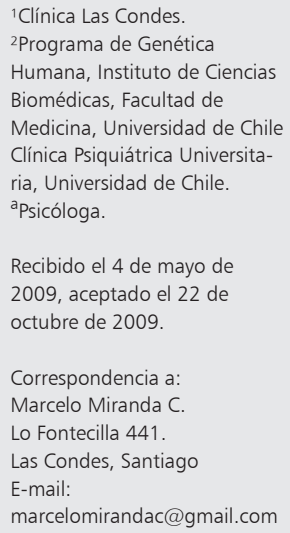

"Escribo para ausentarme"

"A menudo necesitamos del delirio para mantenernos de algún modo a flote en el oleaje de la vida"

\section{Robert Walser}

$\mathrm{R}$ obert Walser (Figuras 1b y 2), brillante escritor del siglo XX, deja de escribir tempranamente, cuando sólo tenía 50 años, para internarse por 3 décadas en un sanatorio mental hasta su muerte. Este hecho constituye una de las tragedias que probablemente han tenido influencia en el desarrollo de la literatura del siglo XX. La originalidad de su aporte, aún hoy de escasa difusión, y la influencia en éste de su controvertida enfermedad mental, hacen muy interesante difundirlo en nuestro medio.

\section{Datos biográficos}

Walser nació en Biel, Suiza en 1878. Era el antepenúltimo hijo de una familia de ocho hermanos, cuyos padres eran pastores protestantes ${ }^{1,2}$. Autodidacta, reconoció haber estudiado en un colegio que parodió en su obra "Jacob von Gunten" (1909), llamándolo "el Instituto Benjamenta", dónde sólo formaban "ceros a la izquierda"”.Walser siempre fue un trotamundos, acogido entre otras ciudades por Basilea, Zurich, Viena, Stuttgart, Munich, Berlín, Ginebra y Berna. Sólo en esta última se conocen hasta 14 domicilios diferentes donde residió $^{1,2}$. En relación a esta característica de su vida afirmó en uno de sus textos: "Una maleta es toda tu casa en este mundo"'.

Empezó a trabajar como botones en un banco a los 14 años, mientras su sueño era convertirse en comediante en un teatro de aficionados. Estudió finalmente para mayordomo, empleo en el que duró poco, como en todos, dedicándose luego a bibliotecario.

Completamente incomprendido, con nulo éxito comercial, vivió en la pobreza y producto de una enfermedad mental fue internado a fines de la década de los años 20 en los sanatorios de Waldau por 4 años y luego en Herisau, Suiza, dónde permanecerá por 23 años más. Al ingresar a este último lugar dijo: "Me he internado no para 
escribir sino para enloquecer" ${ }^{\prime \prime 2}$. Ya una década antes, en 1921, había presentado alucinaciones auditivas y arrebatos de agresividad. Estando en un restaurante les gritó a algunos comensales vecinos "hasta cuando susurran"4. En este período además, abusó del alcohol.

Mantuvo una permanente tendencia a la sole- dad. El escritor Martin Waiser lo describió como "el más solitario de los escritores solitarios". Nunca logró tener una relación de pareja, y se involucró en múltiples trabajos mal remunerados y que le exigian poco en términos intelectuales: se desempeñó como copiador de textos, ayudante de un notario, empleado de oficina, etc.

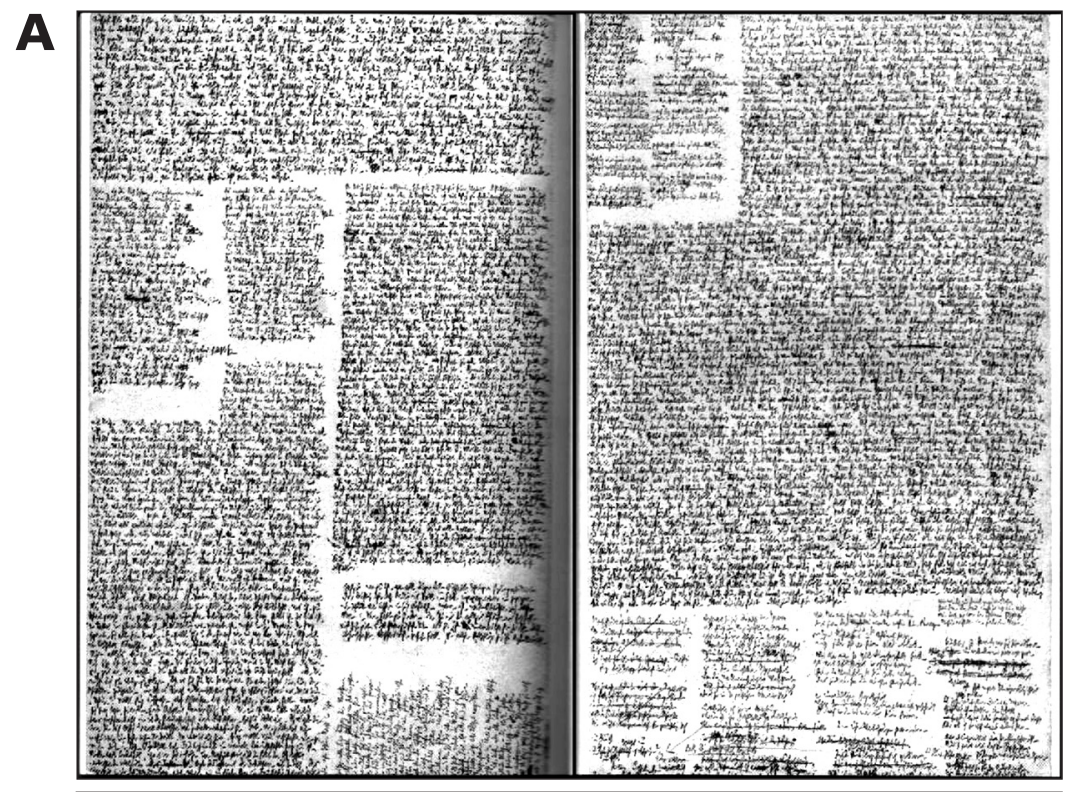

B

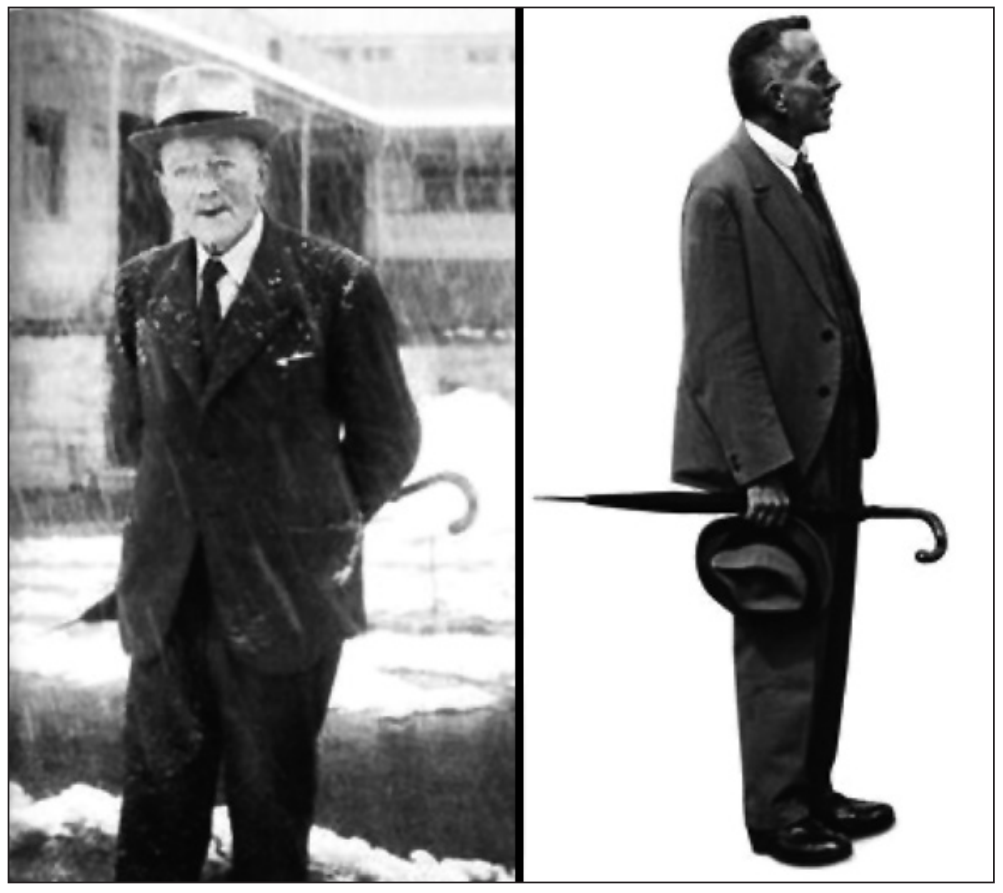

Figura 1. A) Los microgramos de Walser, con una escritura de no más de 1 a $2 \mathrm{~mm}$ de altura, sólo recientemente descifrados y publicados. B) Fotografías de Walser en su sanatorio y en uno de tantos paseos, no dejaba su paraguas aún en días soleados $^{13}$. 

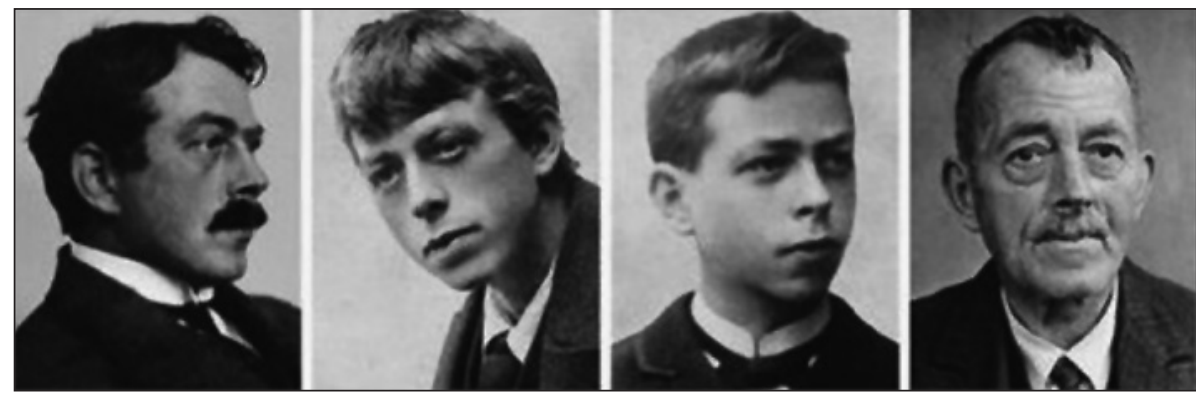

Figura 2. Robert Walser a distintas edades, la última foto de la izquierda ya es de su último año de vida ${ }^{13}$.

En su familia existían varios casos de trastornos mentales: su madre, depresiva, y dos de sus hermanos con esquizofrenia, uno de los cuales se suicidó ${ }^{5}$.

A pesar de que Walser no tuvo éxito literario y siempre tuvo gran dificultad para publicar, su obra llegó a ser admirada por escritores de gran relevancia como Kafka y Hermann Hesse. Este último señaló "Si los poetas como Walser se contaran entre los espíritus dirigentes ya no habría guerras, y si tuviera cien mil lectores el mundo sería mejor. Sea como fuere, el mundo está justificado por haber gente como Walser"2,4. Otros autores como Robert Musil, Thomas Mann, Elias Canetti y más recientemente Vila-Matas en sus libros "Bartleby y Compañía", "El Mal de Montano" y "El Dr Pasavento", han contribuido a su revaloración. Elías Canetti comentó: "De todos sus contemporáneos, Robert Walser se ha convertido a mis ojos, exceptuando a Kafka que no existiría sin él, en el más importante"2.

\section{Su peculiar estilo literario}

La obra de Walser estuvo dedicada a mostrar hechos simples de la vida diaria y transmitir la sensación de maravilla que éstos le producían. Esto lo hace en un estilo particular, lleno de una sutil ironía. Sin embargo, tras esta apariencia de sarcasmo, su obra refleja una angustia no reconocida que Elías Canetti describe así: "Durante toda su vida, niega lo esencial, lo más hondo: su propia angustia", apuntando a ese dolor esencial que subyace a la obra de Walser. Es posible observar que su aparente éxtasis de jovialidad se desintegra en un vacío, en una tremenda soledad. A su hermana le escribió "es mejor vivir enlodado que triste. Dios odia a los tristes"2, refiriéndose a la incomodidad del trabajo, a los esfuerzos que debían llevar a cabo por la necesidad de supervivencia, algo que siempre lo agobió. Tal vez, la inusual alegría, humor y la frecuente ironía de sus frases fueran su defensa frente a tanta adversidad.

Los personajes casi anónimos y fugaces, la falta de hogar, lo provisional de sus existencias, son parte de su temática. La existencia humana, en la visión de Walser, consiste en una total superficialidad. Walter Benjamín dijo acerca de él: "Podría decirse que al escribir se ausenta". Sus opiniones se ven unidas por un hilo que parece imperceptible: es tal la variedad de frases luminosas, apuntes y parodias que, como si se trataran de meras acotaciones circunstanciales lanzadas al aire, revelan matices insospechados en los objetos, incluso en aquellos que creíamos más familiares y conocidos. Walser da a las cosas cotidianas cierta cualidad críptica, desconcertante, las envuelve en una atmósfera sensitiva y banal que es genial. Walser, expresó muy bien en este aforismo, el sentido de su arte: "No hace falta ver nada extraordinario. Ya es mucho lo que se ve". Walser revalora al antihéroe, a los limitados, los humildes, empequeñecidos; él mismo afirmaba que sólo se sentía "cómodo y feliz en las regiones aparentemente inferiores"

Walser es un verdadero miniaturista en el sentido literal. Papeles de distinto tamaño y textura, determinarán una forma de escritura con una letra minúscula a lápiz (de 1 a $2 \mathrm{~mm}$ de altura máxima) llamada "Microgramas" (Figura 1a), realizados entre 1924 y 1932. Estos "Microgramas" son su última obra, y corresponden a cerca de 526 artículos de prosa breve, rescatados por su albacea y amigo Carl Seelig. Estos manuscritos fueron descifrados pacientemente en un período de más de 20 años por los estudiosos suizos Bernard Etche y Werner Morlang ${ }^{7}$. 


\section{La personalidad de Walser}

Walser se describe a sí mismo como: “... una entidad perdida y olvidada en la inmensidad de la vida" y refiriéndose a su relación con el mundo: "qué desapasionado, prosaicamente práctico, noblemente soso es nuestro tiempo. Aunque tal vez tenga también su lado bueno: uno puede distinguirse por su extravagancia".

Su visión es premonitoria en relación a que la alienación y uniformidad cultural que venía adosada a la modernidad, se abrirían paso inexorablemente en el mundo occidental. En su vida aislada, con escasez de relaciones, así como en las características de su escritura, con estilo conciso, a veces muy ambiguo, y con la impresión de no tener un hilo coherente, pueden verse los inicios de su enfermedad psicótica: “..deja apreciada dama, que te haga llegar la buena nueva que abre la boca asombrada de que tú la escuches, se acaricia o se frota la oreja y pretende decirte que una vez servidor se quedó boquiabierto ante una librería en cuyo escaparate estaba expuesto un libro titulado "Bajo el látigo de la polaca", y que también ayer me entregué a los placeres del baño, donde tuve la ocurrencia de comportarme como un mendigo que tiene miedo al agua y al que nadie acostumbró de pequeño al aseo personal"'.

Nunca pudo establecerse y no logró la más mínima posesión material: no tuvo casa jamás, ni una vivienda duradera, ni un solo mueble y mantenía escasa pero pulcra ropa. No poseía libros, y en opinión de uno de sus escasos biógrafos, Sebald, ni siquiera conservaba los que él mismo había escrito $^{2}$. Los que leía eran casi siempre prestados. Hasta el papel de escribir del que se servía era de segunda mano.

Walser reconoce una gran capacidad para amar que es incomprendida: "Soy dueño de un enorme capital de fuerza amatoria, y cada vez que salgo a la calle termino por coger cariño a alguna cosa, a alguna persona" ${ }^{\prime 10}$. Se queja de la recepción de esta postura: "hoy en día, se pretende meter enseguida en la lista negra de los raros a todo aquel que sea aún un poco dueño de sí mismo, lo que da brillante testimonio de la trágica falta de consideración, así como de una negligencia, lamentablemente demasiado arraigada en la sociedad, en los asuntos del trato y las relaciones humanas". Sólo conocemos un intento de relación amorosa, frustrada por lo demás, con Frieda Mermet, viuda, quien tenía su misma edad, era amiga de su hermana y dueña de una lencería, quien recibió al menos dos declaraciones de amor de Walser por carta. Así escribe el 7 de agosto de 1918: “'le gustaría señora Mermet, poseerme en cuerpo y alma?”, tres meses más tarde, insiste: "creo que sería hermoso ser su marido"10. La señora Mermet no aceptó, si bien siguió siendo destinataria de sus cartas más intimas y una amiga fiel hasta el ingreso de Walser al sanatorio de Herisau. Este rechazo ha sido considerado como un posible factor gatillante en el quiebre mental de Walser. La disposición tan extrema para amar de Walser no depende en absoluto de la correspondencia de ese amor. "Privarse del amor, eso es amar", "Si me prohíben amar amo diez veces más. Todo lo prohibido vive diez veces más". Walser necesita a las mujeres como encarnación y catalizador de una personalidad mejor, pues su amor hacia ellas le estimula ante todo a conocerse a sí mismo y a desarrollar su propia imagen ideal a partir de ellas ${ }^{10}$. Cuando esto sucede, se conoce a sí mismo tan intensamente que ya no es necesaria la correspondencia de su amor. Pues escribiendo se ha erigido un mundo a su medida que supera la realidad. "Para el hombre la mujer es algo que, a menudo sin conocerlo, necesita para fines más altos" escribe en su novela "El Bandido" (1925)

Walser disfrutaba del paseo y del andar sin rumbo fijo, lo apasionaban los detalles y lo efímero, la dificultad de no ser nadie o lo absurdo que puede ser el amor. Siempre, en todos sus trabajos en prosa, se percibe el deseo de estar sobre la pesada vida terrestre, desaparecer suavemente y sin ruido hacia un lugar más libre. En una de sus mejores novelas, "Jakob von Gunten"3, leemos: "Las fatigas, los groseros esfuerzos que se precisan para alcanzar en este mundo honores y famas no están hechos para $m i$ ". En el fondo del arte de Walser hay un rechazo al poder, a la dominación: "Soy común, es decir, nadie", afirma el protagonista de esta obra. En una de sus mejores obras: "El Paseo" $(1917)^{6}$, inicia el breve relato con estas simples palabras. "Declaro que una hermosa mañana, ya no sé exactamente a qué hora, como me vino en gana dar un paseo, me planté el sombrero en la cabeza, abandoné el cuarto de los escritos o de los espíritus, y bajé la escala para salir a un buen paso a la calle". Contempla la belleza y exhuberancia de la plaza cercana, los jardines, los árboles; la hermosa voz de una mujer que canta un aria en una ventana, en suma, la naturaleza desnuda ante sus ojos; los de un poeta. El paseo 
semeja una fiesta de los sentidos para este lírico exaltado. Afirmaba: "es divinamente hermoso y bueno, sencillo y antiquísimo, ir a pie”.

\section{El diagnóstico de Walser}

Aún existe controversia acerca de si Walser tuvo o no una esquizofrenia ${ }^{2,5}$. Para uno de sus biógrafos más exhaustivos, Bernhard Etche, quien se entrevistó con algunos de los psiquiatras que lo atendieron, como Spoerri, afirmaba que éstos mantuvieron dudas acerca del diagnóstico. Para Lyons y Fitzgerald ${ }^{5}$, en uno de los pocos trabajos que analiza la psicopatología de Walser, el escritor suizo cumple criterios tanto para un Síndrome de Asperger como para un trastorno de personalidad esquizoafectivo, pero no los criterios DSM IV ${ }^{11}$ para Esquizofrenia. De los criterios que apoyan el diagnóstico: alucinaciones, lenguaje desorganizado, conducta catatónica y síntomas negativos como afecto aplanado, lenguaje empobrecido y disminución de iniciativa, Walser sólo presentó alucinaciones. Para realizar el diagnóstico deben estar presentes 2 o más de esos síntomas. Las alucinaciones también es posible observarlas en individuos con un Síndrome de Asperger sometido a mucho estrés y ansiedad, y efectivamente los episodios psicóticos de Walser coinciden con mucha angustia. El diagnóstico de Asperger se fundamenta en la temprana presencia de retraimiento, ausencia de amigos, marcada incapacidad de desarrollar relaciones con pares y ausencia de reciprocidad social o emocional. Walser efectivamente era muy tímido, introvertido, socialmente torpe y receloso de la gente. Era incapaz y temeroso de formar relaciones personales y responder a los otros de una manera con significado emocional ${ }^{4}$. En la novela autobiográfica "Los Hermanos Tanner" (1907)", el protagonista, dice "Realmente no estoy hecho para la amistad". Walser reúne las características de una personalidad autista como la describió Asperger, quien enfatizó los intereses sofisticados, inteligencia sobre el promedio, creatividad, originalidad de pensamientos y talentos que presentaban algunos de sus pacientes. Se postula que otros notables portadores del síndrome de Asperger fueron el filósofo Wittgenstein y el gran pianista Glenn Gould.

Su hermana Lisa fue quien lo internó en una casa de enfermos mentales en la población de Waldau en enero del año 1929. “¿Estamos haciendo lo conveniente?", le preguntó Robert ya en la puerta ${ }^{1,2}$. Por esa época escribió que había intentado varias veces suicidarse, pero que era incapaz de hacer correctamente un nudo. En los registros médicos se describen al ingreso síntomas como depresión, incapacidad para trabajar, dificultades para concentrarse, insomnio, temores nocturnos, manía persecutoria y algunos pensamientos suicidas, y se reconoce la presencia de alucinaciones auditivas. Toda esta sintomatología habría cedido al cabo de 6 semanas ${ }^{5}$.

El diagnóstico realizado fue el de esquizofrenia. Su hermana optó por declararlo interdicto y si bien los médicos no vieron después de algunos meses razón para que siguiera interno, su hermana rechazó recibirlo. Sin opciones, Walser decidió seguir en el sanatorio.

Hay cierta analogía entre su situación y la del gran poeta alemán Hölderlin. Haciendo referencia a él, y al silencio de Hölderlin a lo largo de los treinta y seis años que pasó encerrado en la torre de Tubinga, Walser afirmó: "Estoy convencido de que, en su largo período final, no fue tan desdichado como se complace en pintárnoslo los profesores de literatura. Poder dedicarse tranquilamente a soñar por los rincones, sin tener que estar haciendo los deberes todo el rato, no es ningún martirio. jSólo la gente hace que lo sea!"'.

Carl Seelig, quizá el único amigo de Walser y su albacea, escribió "Paseos con Robert Walser"1, obra que describe 20 años de largas caminatas con el escritor suizo ya internado en Herisau. Contiene valiosísima información de las conversaciones e impresiones de Walser. Seelig retrata a un Walser que ha enmudecido, un poeta que "tuvo el tacto suficiente como para apearse de la vida". Walser tenía sólo cincuenta años y había dejado de escribir contentándose con la vida que llevaba de paciente en el sanatorio mental. Ayudaba en la limpieza de la cocina del hogar, clasificaba la basura, o leía alguna novela de autores como Julio Verne, en una postura rígida en un rincón. Las notas relativas a estos paseos nos revelan a un Walser que no parece en absoluto un enfermo mental, sino al contrario, un hombre muy sabio.

La prosa tan particular del escritor suizo constituye uno de los logros más originales de la literatura del siglo XX, un siglo que sobrevaloró la innovación. La originalidad de la obra de Walser es espontánea, no buscada o deseada por el autor.

Murió mientras paseaba en la nieve, en una de 


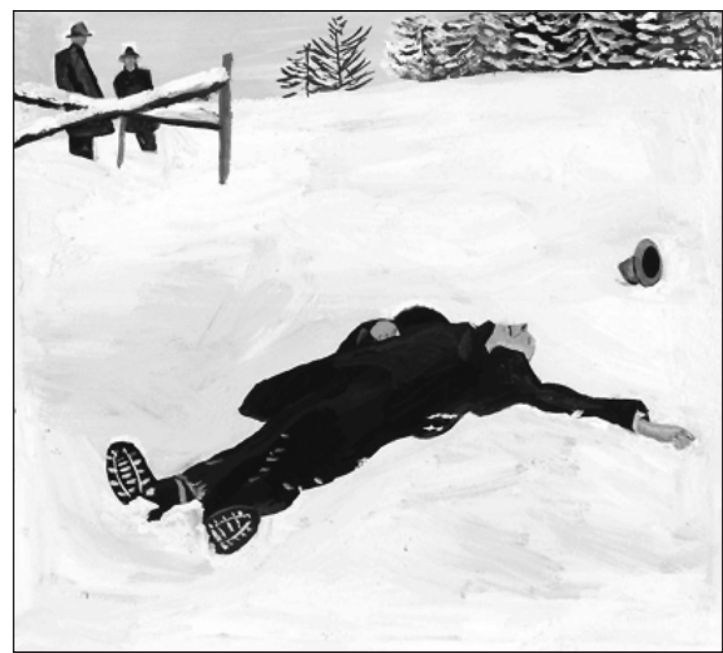

Figura 3. Dramática fotografía del hallazgo de Walser muerto en uno se sus incontables paseos, el día de Navidad de $1956^{13}$.

sus incontables caminatas diarias, en la Navidad del año 1956, en Suiza cerca del sanatorio de Herisau (Figura 3). Fue encontrado por unos niños. Curiosamente, Walser parece haber anticipado su muerte en la descripción que hace del fallecimiento del protagonista de la novela "Los Hermanos Tanner". En ella Sebastián, un poeta, es encontrado muerto en la nieve bajo un cielo constelado. Quién lo encuentra es Simón su hermano, cuyas palabras parecen una autoelegía anticipada: "con que nobleza ha elegido su tumba. Yace en medio de espléndidos abetos verdes, cubiertos por la nieve. No quiero avisar a nadie. La naturaleza se inclina a contemplar a su muerto, las estrellas cantan dulcemente en torno a su cabeza y las aves nocturnas graznan. Es la mejor música para alguien que no tiene oído ni sensaciones".

En Walser se hace verdad lo que afirma el escritor francés y Premio Nobel, André Gide (18691951). En su diario, Gide escribió el 6 de febrero de 1944: “...creo que las enfermedades son llaves que nos pueden abrir ciertas puertas. Hay un estado de buena salud que no nos permite comprenderlo todo, de alguna manera las enfermedades pueden favorecer las actividades creativas" 12 . G. Sebald, en su libro sobre Walser llamado "El Paseante Solitario", comenta la novela "El Bandido" y considera que el escritor suizo, al escribirla, se dio cuenta de que era precisamente el riesgo de enajenación mental lo que le permitía a veces una agudeza de observa- ción y expresión que es imposible cuando se está plenamente sano. Con respecto a esto, Walser hizo el siguiente llamado en esa novela: "no leáis siempre y de manera exclusiva esos libros sanos; acercaos un poquito a la llamada literatura enfermiza, de la que tal vez podáis sacar un consuelo vital".

Si bien la escritura de Walser puede parecer psicótica, el hecho de haberse mantenido escribiendo al menos 4 años luego de haber sido internado, no es compatible con la declinación cognitiva que se observa en pacientes esquizofrénicos. Concordamos con que su psicopatología podría explicarse mejor por un Síndrome de Asperger.

Sólo en los últimos 15 años Walser está siendo traducido al castellano. Gran parte de sus obras ya están publicadas gracias a la iniciativa de Editorial Siruela. Este logro está permitiendo algo que el propio Walser no hubiera querido, obtener un reconocimiento más universal que indudablemente merece.

Agradecimientos: Agradecemos los comentarios y sugerencias de los Dres. Pedro Retamal y Rodrigo Erazo, Psiquiatras del Departamento de Psiquiatría de la Facultad de Medicina Sede Oriente y de Clínica Las Condes, respectivamente.

\section{Referencias}

1. Seelig C. Paseos con Robert Walser. Ed Siruela, Barcelona 2000.

2. Sebald G. El Paseante Solitario. Ed Siruela, Barcelona 2007.

3. Walser R. Jakob von Gunten. Ed Siruela Barcelona 2003.

4. Vila-Matas E. El Doctor Pasavento. Ed Anagrama, Barcelona 2007.

5. Lyons V, Fitzgerald M. The case of Robert Walser. Ir J Psych Med 2004: 21; 138-422.

6. Walser R. El Paseo. Ed Siruela Barcelona 1996.

7. Walser R. Microgramas. Ed Siruela Barcelona 2007.

8. Walser R. El Bandido. Ed Siruela Barcelona, Barcelona, 2004.

9. Walser R. Los Hermanos Tanner. Editorial Siruela, Barcelona, 2000.

10. Michels V. Epílogo en: Walser R. Historias de Amor. Ed Siruela Barcelona 2003.

11. American Psychiatric Association. DSM-IV.Nueva York 1994.

12. Gide A. Diario. Losada, Buenos Aires 1963.

13. http://www.walser-archiv.ch/, visitado el 23 de septiembre 2009. 